\title{
Effect of esomeprazole versus placebo on pulmonary exacerbations in cystic fibrosis
}

Emily DiMango ${ }^{1 *}$, Patricia Walker ${ }^{2}$, Claire Keating ${ }^{1}$, Maria Berdella², Newell Robinson ${ }^{1}$, Elinor Langfelder-Schwind ${ }^{2}$, Diane Levy ${ }^{3}$ and Xinhua Liu ${ }^{3}$

\begin{abstract}
Background: Gastro esophageal reflux (GER) is common in cystic fibrosis (CF) and may contribute to lung disease. Approximately $50 \%$ of patients with cystic fibrosis are being treated with proton pump inhibitors (PPIs).

Methods: In a randomized controlled study in adults, we compared treatment with esomeprazole $40 \mathrm{mg}$ twice daily versus placebo in patients with CF and frequent respiratory exacerbations over a thirty-six week treatment period to determine effect on time to first exacerbation and other health related outcomes.

Results: 17 patients without symptoms of GER were randomized and 15 completed the study. 13 subjects underwent 24 hour ambulatory $\mathrm{pH}$ probe monitoring; $62 \%$ had $\mathrm{pH}$ probe evidence of GER. Forty one percent of subjects had a pulmonary exacerbation during the study. There was no significant difference in time to first pulmonary exacerbation (log rank test $p=0.3169$ ). Five of nine subjects in the esomeprazole group compared with 2 of eight subjects in the placebo group experienced exacerbations (esomeprazole vs. placebo: odds ratio $=3.455$, $95 \% \mathrm{Cl}=(0.337,54.294)$, Fisher's exact test: $\mathrm{p}=0.334)$. There was no change in Forced Expiratory Volume in one second, Gastroesophageal Symptom Assessment Score or CF Quality of Life score between the two treatment groups.

Conclusions: There was a trend to earlier exacerbation and more frequent exacerbations in subjects randomized to esomeprazole compared with placebo. The effect of proton pump inhibitors on pulmonary exacerbations in CF warrants further investigation.
\end{abstract}

Clinical trials registration: Clinicaltrials.gov, NCT01983774

\section{Background}

Gastroesophageal reflux (GER), both symptomatic and silent, is frequent in patients with cystic fibrosis (CF), and is often regarded as playing a role in the pathogenesis of CF related lung disease [1-4]. The overall prevalence of GER in CF is not well established, but is reported to be as high as $80 \%$ when diagnosed by esophageal $\mathrm{pH}$-probe monitor in CF adults [3,5]. One study reported that 91\% of patients with CF awaiting lung transplant had evidence of GER by $\mathrm{pH}$ probe monitoring [6]. Symptoms of lung disease in CF may overlap with pulmonary symptoms of gastroesophageal reflux, making it difficult to distinguish between the two conditions and often leading to treatment of both conditions. In 2010 in the US, $48 \%$ of adults

\footnotetext{
* Correspondence: ead3@columbia.edu

${ }^{1}$ Columbia University Medical Center Department of Medicine, 622 West 168th Street, New York, NY 10032, USA

Full list of author information is available at the end of the article
}

and $51 \%$ of children with CF were being treated with proton pump inhibitors [7].

Several studies have suggested that patients with CF who have GER have more severe lung disease with lower pulmonary function and increased numbers of respiratory exacerbations $[2,8]$. In a prospective study, Button etal demonstrated that children with CF receiving modified chest physiotherapy with avoidance of head in the tilt down position not only had reduced episodes of GER as measured by ambulatory $\mathrm{pH}$ probe, but also had reduced need for antibiotics, reduced number of hospital days and improved lung function over a five year period [9]. The European Epidemiologic CF Registry reported that patients with CF and GER had lower pulmonary function than those without GER [8]. A recently conducted retrospective study of Nissen fundoplication in patients with CF and GER showed a significant decline 
in pulmonary exacerbations and improvement in forced expiratory volume in one second $\left(\mathrm{FEV}_{1}\right)$ during the two years following surgery compared to the two years preceding surgery [10]. Despite considerable evidence that GER is common in CF and may be associated with more severe lung disease, the effect of acid suppressor therapy on improving lung function and reducing pulmonary exacerbations has not been prospectively studied.

Proton pump inhibitors (PPIs) suppress the production of gastric acid and several studies have tested their effectiveness in improving pulmonary outcomes in chronic respiratory diseases. Studies of PPI therapy in asthma have inconsistently demonstrated beneficial effects $[11,12]$, and retrospective studies in idiopathic pulmonary fibrosis suggest stabilization of lung function and improved survival with acid suppression [13,14], Among individuals with CF, PPIs are likely initiated for a variety of reasons including improved efficacy of pancreatic enzymes in a higher $\mathrm{pH}$ environment, as well as treatment of cough or other respiratory or gastrointestinal complaints thought to be possibly caused by GER. Use of these agents however, may be associated with risk $[15,16]$. Use of PPIs in both hospitalized and ambulatory patients has been shown to be associated with an increased risk of pneumonia [15-18]. Furthermore, PPIs have been implicated in accelerated bone loss $[19,20]$. We compared treatment with esomeprazole versus placebo in a pilot study of patients with $\mathrm{CF}$ and frequent respiratory exacerbations to determine whether suppression of gastric acid leads to longer time to first pulmonary exacerbation and improvements in other health related outcomes.

\section{Methods}

We conducted a randomized, placebo-controlled double blind trial of esomeprazole in adult patients with cystic fibrosis. Adults with cystic fibrosis were enrolled from the clinical practices of two adult cystic fibrosis programs in New York City. Inclusion criteria were age of 18 years or older and two to four respiratory exacerbations per year requiring oral and/or intravenous antibiotics for each of the two years prior to study entry. At the time of enrollment, subjects had to have been on a stable maintenance medical regimen for at least six weeks. Participants were excluded if they were being treated with PPIs, were receiving enteral feeds, had smoked cigarettes within the previous six months, had previous anti-reflux surgery or clinical indications for acid-suppressor treatment (i.e. two or more episodes per week of heartburn requiring antacids). Participants were also excluded if they were being treated with medications that interact with proton pump inhibitors (azoles, iron, anti-coagulants), were pregnant or had a pulmonary exacerbation requiring antibiotics within the previous two weeks. All participants provided written informed consent statements that had been approved by the Columbia University Institutional Review Board (IRB AAAC8262) and the Beth Israel Medical Center Institutional Review Board (IRB 074-10).

After the screening visit, those subjects who met eligibility criteria were enrolled in a 2 week run-in period during which time they underwent 24-hour ambulatory $\mathrm{pH}$ probe monitoring. Calibrated $\mathrm{pH}$ probes were placed in the distal esophagus using esophageal manometry, $5 \mathrm{~cm}$ above the lower esophageal sphincter. Criteria for an acceptable study included total recording time of at least 16 hours, with at least one meal and 2 hours of recumbency. A study was considered positive for distal GER if the distal $\mathrm{pH}$ was less than 4 more than $5.8 \%$ total time, or more than $8.2 \%$ of upright time, or more than $3.5 \%$ of supine time [21,22]. Meal times were excluded in the analysis to avoid false-positive data. A single gastroenterologist at each of the two centers reviewed studies; study subjects and study investigators were blinded to the results.

Fourteen days after screening, subjects were randomly assigned in a 1:1 ratio to receive either esomeprazole $40 \mathrm{mg}$ twice daily or matching placebo, regardless of $\mathrm{pH}$ probe results. The Columbia University Research Pharmacy prepared study medication. At the randomization visit, baseline spirometry, CF related quality of Life (CFQ-R QOL) [23] and Gastroesophageal Symptom Assessment Score (GSAS) measuring number and severity of reflux symptoms [24] were collected. Randomization was stratified based on study center and $\mathrm{FEV}_{1}$ decile. Primary outcome measure was time to first pulmonary exacerbation. Secondary outcomes included exacerbation rate, change in $\mathrm{FEV}_{1}$, forced vital capacity (FVC), CFQ-R QOL score and GSAS score. After randomization, participants returned to the clinic every six weeks for 36 weeks. Outcome measures were re-assessed at 12, 24 and 36 weeks after randomization. Subjects were instructed to notify the study site if they had signs or symptoms of a pulmonary exacerbation or if they were treated for a pulmonary exacerbation. Pulmonary exacerbation was defined as initiation of treatment with intravenous or oral antibiotics for 7 or more days based on respiratory symptoms at the discretion of the treating physician $[24,25]$. Additionally, at each visit, subjects answered questions from a checklist to ensure that all exacerbation events were captured.

\section{Statistical analysis}

Summary statistics were calculated for sample characteristics of each treatment group. Fisher's exact method and Wilcoxon rank sum test was used to detect treatment group differences in baseline binary and quantitative variables respectively. Kaplan-Meier product limit method was used to estimate cumulative probability 
curve for time to first exacerbation in each treatment group and log rank test was used to detect group difference in the curve. Rate of exacerbation defined as number of exacerbations per person year was calculated by treatment group and negative binomial model was used to examine treatment group differences. Linear model with repeated measures were used to examine treatment group difference in $\mathrm{FEV}_{1}$, FVC, CFQ-R and GSAS over time. For participants who were withdrawn after randomization, longitudinal analyses compared each value at the start of the treatment period to the last observed value carried forward for each variable examined.

\section{Results}

Twenty one subjects were screened; two subjects withdrew consent before randomization, one subject was ineligible based on daily symptoms of GER (an indication for acid suppressor therapy) and one subject was ineligible due to frequency of exacerbations being above the threshold for enrollment. Of the 17 subjects who were randomized, four were unable to tolerate insertion of the $\mathrm{pH}$ probe but remained in the study. Fifteen subjects completed the study; all randomized subjects are included in the analysis (Figure 1). There were no significant differences between subjects randomized to placebo and those randomized to esomeprazole, though the placebo group tended toward lower lung function, more frequent exacerbations and lower body mass index (BMI) (Table 1). Of the subjects who underwent 24 hour $\mathrm{pH}$ probe monitoring, five of eight subjects $(62.5 \%)$ in the esomeprazole group and three of five subjects $(60 \%)$ in the placebo group had probe evidence of GER. There were no significant differences in baseline characteristics between subjects with and without evidence of distal GER (Table 2).

Forty one percent of 17 subjects had a pulmonary exacerbation during the study. Five of nine subjects in the esomeprazole group compared with 2 of 8 subjects in the placebo group experienced exacerbations (esomeprazole vs. placebo: odds ratio $=3.455,95 \% \mathrm{CI}=(0.337$, 54.294). There was no significant difference in time to first pulmonary exacerbation between the esomeprazole and placebo groups (log rank test $\mathrm{p}=0.3169$ ) (Figure 2). Similarly, there was no significant difference between groups in exacerbation rate during the study period (2.04 exacerbations per person year in esomeprazole group 95\% CI $(1.33,4.14)$ compared with 0.59 exacerbations per person year in placebo group $(95 \%$ CI $(0.19$, 1.82), $\mathrm{p}=0.07$. There was no significant change in $\mathrm{FEV}_{1}$ percent predicted or FVC percent predicted in either group over the study period, $\mathrm{p}=0.23$ and 0.58 , respectively, and there was no difference between groups in change in $\mathrm{FEV}_{1}$ or $\mathrm{FVC}$ percent predicted from baseline to end of study (Figure 3). GSAS and CFQ-R score did

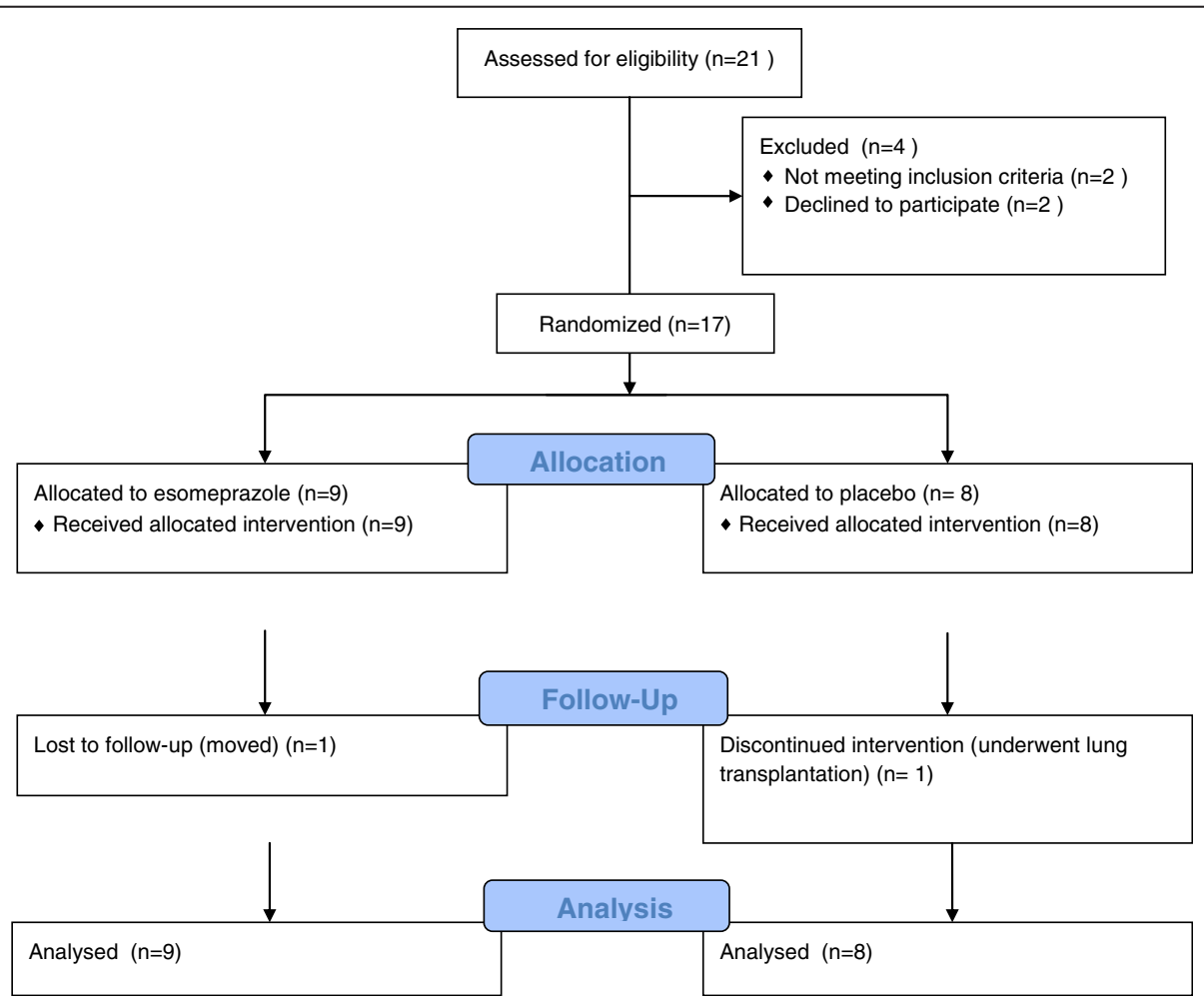

Figure 1 Flow diagram for screened and enrolled subjects. 
Table 1 Baseline characteristics of subjects by treatment assignment

\begin{tabular}{llll}
\hline & $\begin{array}{l}\text { Esomeprazole } \\
(\mathbf{n = 9 )}\end{array}$ & $\begin{array}{l}\text { Placebo } \\
(\mathbf{n}=\mathbf{8})\end{array}$ & p value \\
\hline Reflux present on pH probe & $5 / 8(62 \%)$ & $3 / 5(60 \%)$ & 0.42 \\
Male (\%) & 67 & 75 & 0.38 \\
Pseudomonas present (\%) & 89 & 62 & \\
MRSA present(\%) & 0 & 25 & \\
& Mean + SD & Mean + SD & \\
Age (years) & $35.72+9.6$ & $32.81+5.84$ & 0.41 \\
BMI & $24.25+4.72$ & $21.84+3.02$ & 0.21 \\
\# exacerbations past 2 years & $4+0(0)$ & $5.5+1.4(\mathrm{SD})$ & \\
FEV1 (\%) & $58+19$ & $46+21$ & 0.14 \\
FVC (\%) & $74+20$ & $71+16$ & 0.88 \\
FEV1/FVC & $0.63+0.10$ & $0.56+0.15$ & 0.26 \\
GSAS distress score & $0.99+0.61$ & $0.88+1.03$ & 0.28 \\
CFR-QOL score & $72.28+10.32$ & $77.85+18.86$ & 0.34 \\
\hline
\end{tabular}

not change significantly over the study period $(\mathrm{p}=0.27$ and 0.32 , respectively) and there was no difference in change in scores between the two treatment groups.

\section{Discussion}

Individuals with $\mathrm{CF}$ have many predisposing factors to the development of GER including airway hyperinflation, frequent cough, hyperalimentation, delayed gastric emptying, high fat diet and positional changes related to performance of chest physiotherapy [25]. Twenty-four hour esophageal $\mathrm{pH}$ monitoring has the highest sensitivity and specificity for the detection of GER and is widely regarded as the gold standard for quantifying esophageal $\mathrm{pH}$. We demonstrate that the majority of patients with cystic fibrosis in our cohort have evidence of distal esophageal reflux as measured by esophageal $\mathrm{pH}$ monitoring despite absence of symptoms. In the small prospective study reported here, suppression of gastric acid with esomeprazole did not lead to significant improvement in pulmonary outcomes. An unanticipated finding of this study was a trend to earlier exacerbation and more frequent exacerbations

Table 2 Comparison of subjects with and without gastroesophageal reflux as measured by 24 hour ambulatory $\mathrm{pH}$ probe

\begin{tabular}{llll}
\hline & $\begin{array}{l}+\mathbf{p H} \text { probe } \\
(\mathbf{n = 8})\end{array}$ & $\begin{array}{l}-\mathbf{p H} \text { probe } \\
(\mathbf{n}=\mathbf{5})\end{array}$ & $\mathbf{p}$ value \\
\hline Age & $33.8(4.37)$ & $37(16.5)$ & 0.59 \\
FEV1 (\%) & $51(17)$ & $59(20)$ & 0.45 \\
BMI & $23.5(2.7)$ & $21.8(5 / 2)$ & 0.43 \\
GSAS & $0.65(0.29)$ & $0.59(0.21)$ & 0.88 \\
+ exacerbations & $5.5(1.4)$ & $4(0)$ & 0.33 \\
previous two years & & & \\
\hline
\end{tabular}

in patients randomized to esomeprazole compared with placebo.

In 2010, the Cystic Fibrosis Foundation Patient Registry reported that $50.7 \%$ of children less $<18$ years and $48.2 \%$ of adults $>18$ years were being treated with proton pump inhibitors. Though studies have suggested that treatment of GER is associated with improvement in other lung diseases, prospective studies have not been conducted in $\mathrm{CF}$ to determine whether reducing gastric $\mathrm{pH}$ has a beneficial effect on pulmonary exacerbations or other health related outcomes. The possible mechanisms whereby gastroesophageal reflux leads to respiratory symptoms in CF and other chronic lung diseases have not been established. Some investigators speculate that reflux into the esophagus, particularly in the supine position, results in intermittent aspiration of acidic stomach contents into the airways compounding the effects of the vicious cycle of inflammation, infection and progression of lung disease that has been well described in CF. Mendez, et al demonstrated that even after lung transplantation, $90 \%$ of patients with CF had evidence of GER compared with only $54 \%$ of patients who underwent lung transplant for other diseases. The majority of CF patients had evidence of proximal and distal GER [26]. Tracheal acidification has in fact been demonstrated in adults with CF while in the supine position [27]. It is further hypothesized that afferent receptors within the esophageal mucosa, when stimulated by exposure to acid, trigger outputs along motor neurons to the respiratory muscles and tracheobronchial tree, resulting in cough, bronchospasm and perhaps even increase in neutrophilic airway inflammation $[28,29]$. A relationship between GER and the development of obliterative bronchiolitis after lung transplantation, with improved allograft function after Nissen fundoplication has been reported by Davis and colleagues [30]. However, a large prospective study of the effect of PPIs on asthma exacerbations did not show an improvement in asthma outcomes [11].

PPIs address only the acid component of reflux, and there is evidence that non-acid reflux, such as bile salts from the small intestine, may also be lung irritants. Tamhankar and others have demonstrated that omeprazole does not reduce the number of reflux episodes or their duration, but acts to convert acid reflux to less acid reflux [31]. Doumit et al showed that among children with CF, $63 \%$ of reflux episodes were acid compared with $37 \%$ which were non acid [32]. In a study by Pauwels, et al, $56 \%$ of patients with CF had bile acids in the sputum, providing evidence for the aspiration of duodenogastric contents [25]. Furthermore, concentration of bile acids correlated with neutrophil elastase in sputum, degree of lung function impairment and need for IV antibiotic treatment. 


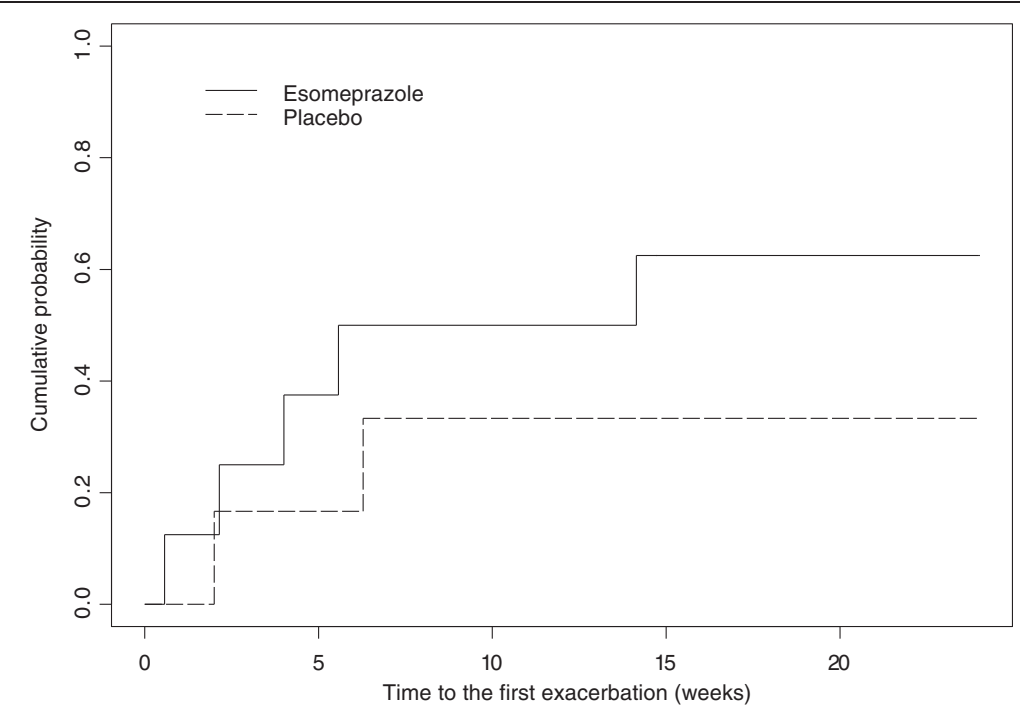

Figure 2 Time to first exacerbation in treatment group assigned to esomeprazole versus placebo. Log rank test $p=0.3169$.

PPIs have the potential to increase the incidence of hospital and community acquired pneumonia, as demonstrated by several retrospective studies of PPI use in both the in-patient and outpatient setting $[15,16]$. Individuals with CF have chronic airway infections with a host of pathogens, notably Pseudomonas aeruginosa and Staphylococcus aureus. Despite widespread use of PPIs in this patient population, their safety and effect on pulmonary outcomes have not been studied.

Our randomized placebo controlled double blind study of the effect of proton pump inhibitors on pulmonary exacerbations in a group of patients with CF and a known history of recurrent exacerbations was designed as a feasibility study and was underpowered to demonstrate a
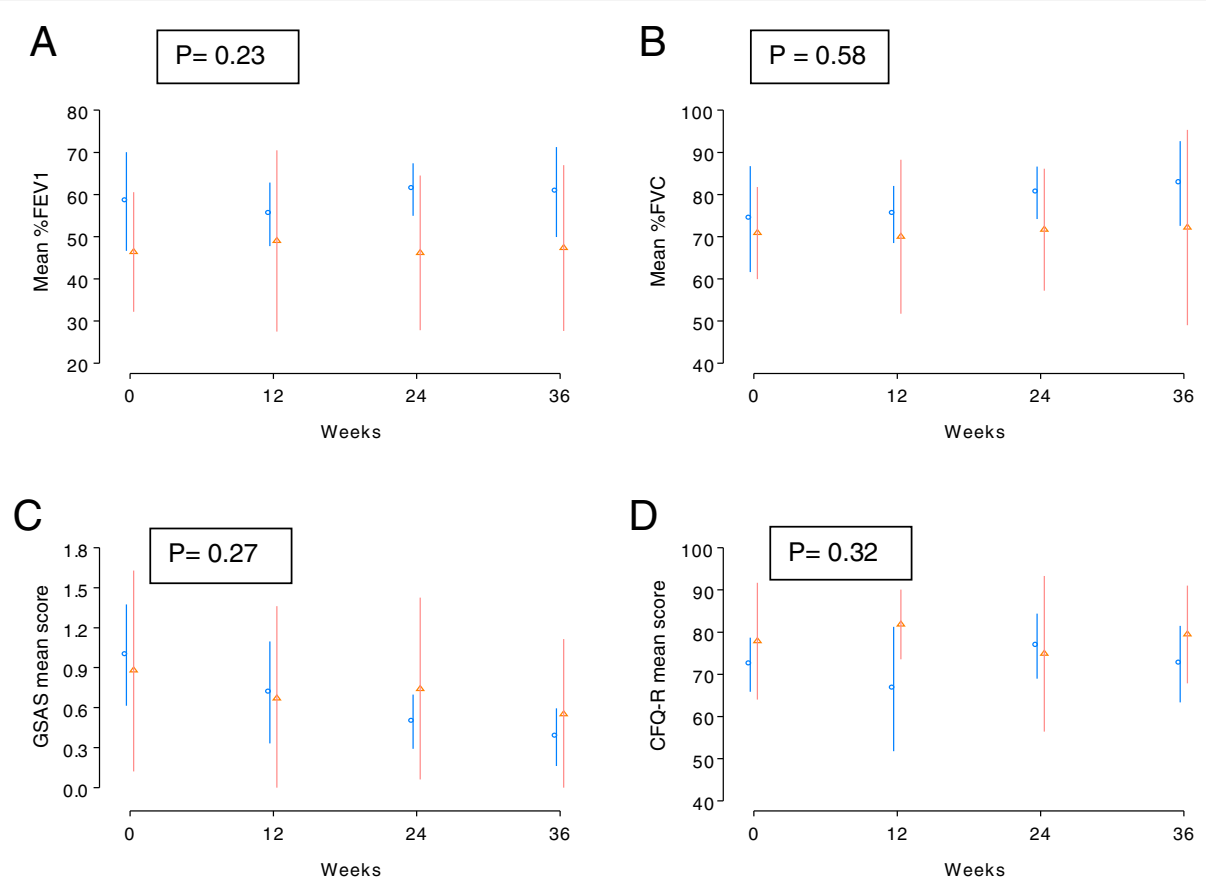

Figure 3 A. Forced Expiratory Volume in 1 second (FEV1) over treatment period. B. Forced Vital Capacity (FVC) over treatment period. C. Gastroesophageal Symptom Assessment Score (GSAS) over treatment period. D. Cystic Fibrosis Quality of Life - revised (CFQ-R) score over treatment period. Blue lines: esomeprazole group; mean with standard deviation. Red lines: placebo group; mean with standard deviation. 
significant effect on respiratory outcomes. We demonstrated that in a population of patients with $\mathrm{CF}$ and recurrent pulmonary exacerbations, $60 \%$ of patients have asymptomatic acid GER. These results are consistent with those reported by Brodzicki et al where $55 \%$ of children with CF had GER, despite the absence of symptoms in many of those patients [33]. There was a trend toward shorter time to first pulmonary exacerbation and higher exacerbation rate in patients randomized to esomeprazole compared with placebo, despite that fact that the placebo group had more frequent exacerbations during the two years prior to study enrollment. Though the study enrolled only subjects with frequent pulmonary exacerbations (between 2 and 4 per year), there was a relatively low incidence of pulmonary exacerbations during the treatment period in that only $42 \%$ of subjects experienced an exacerbation over a thirty-six week period. This may be related to the introduction of new therapies during the study period, such as hypertonic saline and inhaled aztreonam lysine. [34,35].

Our study hypothesized that gastric acid suppression would prolong time to first pulmonary exacerbation, thus adequate gastric acid suppression was an essential component of the study design. Esomeprazole was selected because of its high potency for gastric acid suppression; the twice-daily dose of $40 \mathrm{mg}$ has been shown to effectively suppress gastric acid in about $95 \%$ of patients [30]. 36 weeks was chosen for study duration to allow long enough follow up time for development of respiratory exacerbation in the majority of patients. Our study findings are limited by small sample size without adequate power to detect significant differences between subjects treated with esomeprazole compared with placebo. However, trends regarding frequency of exacerbation and time to exacerbation were consistent in the esomeprazole group. The fact that our results align with reports from several retrospective studies demonstrating an increased risk of lower respiratory tract infections in patients taking PPIs, and that patients with cystic fibrosis chronically harbor bacterial pathogens and develop recurrent pulmonary exacerbations, suggests that further investigation into the possible effects of PPIs on pulmonary infections in CF is warranted.

This work was previously presented in Abstract form at the North American Cystic Fibrosis Conference 2012 [33].

\section{Conclusion}

Asymptomatic gastroesophageal reflux is present in the majority of patients with cystic fibrosis. Risk and benefits of acid suppressive agents in cystic fibrosis require further study.

\section{Competing interests}

Emily DiMango serves on the Advisory Board of Gilead Pharmaceuticals.

Patricia Walker serves as a consultant to Gilead Pharmaceuticals. Claire
Keating reports no Conflict of Interest. Maria Berdella reports no Conflict of Interest. Bryce Robinson reports no Conflict of Interest. Elinor Langfelder-Schwind reports no Conflict of Interest. Diane Levy reports no Conflict of Interest. Xinhua Liu reports no Conflict of Interest.

\section{Authors' contributions}

ED and PW developed the study protocol and oversaw all aspects of the study. CK, MB, ELS and NR conducted study visits and assisted with data analysis. $\mathrm{DL}$ and $\mathrm{XL}$ performed statistical analysis for the study. All authors read and approved the final manuscript.

\section{Acknowledgment}

The authors would like to thank the staff and patients at Columbia University and Beth Israel Adult CF Programs (Victoria Robinson, RN and Carroll Anne Grece, research coordinators). All authors have participated in design and execution of the study and manuscript preparation. Dr. DiMango takes responsibility for the integrity of the work, from its inception to publication. Supported by CFF grant DIMANGO7AO and P30ES009089 from the National Institute of Environmental Health Sciences (NIEHS) (Santella, R) and the Irving Institute for Clinical and translational research UL1 TR000040.

\section{Author details}

${ }^{1}$ Columbia University Medical Center Department of Medicine, 622 West 168th Street, New York, NY 10032, USA. Beth Israel Medical Center Department of Medicine, 10 Nathan D. Perlman Place, New York, NY 10003, USA. ${ }^{3}$ Columbia University Mailman School of Public Health, 722 West 168th Street, New York, NY 10032, USA.

Received: 15 August 2013 Accepted: 13 February 2014 Published: 15 February 2014

\section{References}

1. Gustafsson PM, Fransson SG, Kjellman NI, Tibbling L: Gastro-oesophageal reflux and severity of pulmonary disease in cystic fibrosis. Scand J Gastroenterol 1991, 26(5):449-456. PubMed PMID: 1871537.

2. Palm K, Sawicki G, Rosen R: The impact of reflux burden on Pseudomonas positivity in children with cystic fibrosis. Pediatr Pulmonol 2012, 47(6):582-587. PubMed PMID: 22162484

3. Ledson MJ, Tran J, Walshaw MJ: Prevalence and mechanisms of gastro-oesophageal reflux in adult cystic fibrosis patients. J $R$ Soc Med 1998, 91(1):7-9. PubMed PMID: 9536132

4. Vic P, Tassin E, Turck D, Gottrand F, Launay V, Farriaux JP: [Frequency of gastroesophageal reflux in infants and in young children with cystic fibrosis]. Arch Pediatr 1995, 2(8):742-746. PubMed PMID: 7550838. Frequence du reflux gastrooesophagien chez le nourrisson et le jeune enfant atteints de mucoviscidose.

5. Button BM, Roberts S, Kotsimbos TC, Levvey BJ, Williams TJ, Bailey M, et al: Gastroesophageal reflux (symptomatic and silent): a potentially significant problem in patients with cystic fibrosis before and after lung transplantation. J Heart Lung Transplant 2005, 24(10):1522-1529. PubMed PMID: 16210125

6. D'Ovidio F, Singer LG, Hadjiliadis D, Pierre A, Waddell TK, de Perrot M, et al: Prevalence of gastroesophageal reflux in end-stage lung disease candidates for lung transplant. Ann Thorac Surg 2005, 80(4):1254-1260. PubMed PMID: 16181849.

7. Cystic Fibrosis Foundation Patient Registry: 2010 Annual Data Report. Bethesda M. http://www.cff.org/SearchResults/index.cfm? $c x=014097933530442145544 \% 3$ Amfnlnb3cjhe\&q=annual +report+2010.

8. Navarro J, Rainisio M, Harms HK, Hodson ME, Koch C, Mastella G, et al: Factors associated with poor pulmonary function: cross-sectional analysis of data from the ERCF. European Epidemiologic Registry of Cystic Fibrosis. Eur Respir J 2001, 18(2):298-305. PubMed PMID: 11529288.

9. Button BM, Heine RG, Catto-Smith AG, Olinsky A, Phelan PD, Ditchfield MR, et al: Chest physiotherapy in infants with cystic fibrosis: to tip or not? A five-year study. Pediatr Pulmonol 2003, 35(3):208-213. PubMed PMID: 12567389.

10. Sheikh SI, Ryan-Wenger NA, McCoy KS: Outcomes of surgical management of severe GERD in patients with cystic fibrosis. Pediatr Pulmonol 2012. PubMed PMID: 22949398

11. American Lung Association Asthma Clinical Research C, Mastronarde JG, Anthonisen NR, Castro M, Holbrook JT, Leone FT, et al: Efficacy of 
esomeprazole for treatment of poorly controlled asthma. New Engl J Med 2009, 360(15):1487-1499. PubMed PMID: 19357404. Pubmed Central PMCID: 2974569.

12. Kiljander TO, Harding SM, Field SK, Stein MR, Nelson HS, Ekelund J, et al: Effects of esomeprazole $40 \mathrm{mg}$ twice daily on asthma: a randomized placebo-controlled trial. Am J Respir Crit Care Med 2006, 173(10):1091-1097. PubMed PMID: 16357331

13. Raghu G, Yang ST, Spada C, Hayes J, Pellegrini CA: Sole treatment of acid gastroesophageal reflux in idiopathic pulmonary fibrosis: a case series. Chest 2006, 129(3):794-800. PubMed PMID: 16537884.

14. Lee JS, Ryu JH, Elicker BM, Lydell CP, Jones KD, Wolters PJ, et al: Gastroesophageal reflux therapy is associated with longer survival in patients with idiopathic pulmonary fibrosis. Am J Respir Crit Care Med 2011, 184(12):1390-1394. PubMed PMID: 21700909.

15. Eurich DT, Sadowski CA, Simpson SH, Marrie TJ, Majumdar SR: Recurrent community-acquired pneumonia in patients starting acid-suppressing drugs. Am J Med 2010, 123(1):47-53. PubMed PMID: 20102991.

16. Hermos JA, Young MM, Fonda JR, Gagnon DR, Fiore LD, Lawler EV: Risk of community-acquired pneumonia in veteran patients to whom proton pump inhibitors were dispensed. Clin Infect Dis 2012, 54(1):33-42. PubMed PMID: 22100573.

17. de Jager CP, Wever PC, Gemen EF, van Oijen MG, van Gageldonk-Lafeber $A B$, Siersema PD, et al: Proton pump inhibitor therapy predisposes to community-acquired Streptococcus pneumoniae pneumonia. Aliment Pharmacol Therapeut 2012, 36(10):941-949. PubMed PMID: 23034135.

18. Meijvis SC, Cornips MC, Voorn GP, Souverein PC, Endeman H, Biesma DH, et al: Microbial evaluation of proton-pump inhibitors and the risk of pneumonia. Eur Respir J 2011, 38(5):1165-1172. PubMed PMID: 21478217.

19. Gray SL, LaCroix AZ, Larson J, Robbins J, Cauley JA, Manson JE, et al: Proton pump inhibitor use, hip fracture, and change in bone mineral density in postmenopausal women: results from the women's health initiative. Arch Intern Med 2010, 170(9):765-771. PubMed PMID: 20458083.

20. Lau YT, Ahmed NN: Fracture risk and bone mineral density reduction associated with proton pump inhibitors. Pharmacotherapy 2012, 32(1):67-79. PubMed PMID: 22392829

21. Richter JE, Kahrilas PJ, Johanson J, Maton P, Breiter JR, Hwang C, et al: Efficacy and safety of esomeprazole compared with omeprazole in GERD patients with erosive esophagitis: a randomized controlled trial. Am J Gastroenterol 2001, 96(3):656-665. PubMed PMID: 11280530

22. DeMeester TR, Johnson LF: The evaluation of objective measurements of gastroesophageal reflux and their contribution to patient management Surg Clin North Am 1976, 56(1):39-53. PubMed PMID: 2983.

23. Quittner AL, Buu A, Messer MA, Modi AC, Watrous M: Development and validation of the cystic fibrosis questionnaire in the United States: a health-related quality-of-life measure for cystic fibrosis. Chest 2005, 128 (4):2347-2354. PubMed PMID: 16236893

24. Damiano A, Handley K, Adler E, Siddique R, Bhattacharyja A: Measuring symptom distress and health-related quality of life in clinical trials of gastroesophageal reflux disease treatment: further validation of the Gastroesophageal Reflux Disease Symptom Assessment Scale (GSAS). Dig Dis Sci 2002, 47(7):1530-1537. PubMed PMID: 12141813.

25. Pauwels A, Decraene A, Blondeau K, Mertens V, Farre R, Proesmans M, et al: Bile acids in sputum and increased airway inflammation in patients with cystic fibrosis. Chest 2012, 141(6):1568-1574. PubMed PMID: 22135379.

26. Mendez BM, Davis CS, Weber C, Joehl RJ, Fisichella PM: Gastroesophageal reflux disease in lung transplant patients with cystic fibrosis. Am J Surg 2012, 204(5):e21-e26. PubMed PMID: 22921151.

27. Ledson MJ, Wilson GE, Tran J, Walshaw MJ: Tracheal microaspiration in adult cystic fibrosis. J R Soc Med 1998, 91(1):10-12. PubMed PMID: 9536133.

28. Hamamoto J, Kohrogi H, Kawano O, Iwagoe H, Fujii K, Hirata N, et al: Esophageal stimulation by hydrochloric acid causes neurogenic inflammation in the airways in guinea pigs. J Appl Physiol 1997, 82(3):738-745. PubMed PMID: 9074957.

29. Carpagnano GE, Resta O, Ventura MT, Amoruso AC, Di Gioia G, Giliberti T, et al: Airway inflammation in subjects with gastro-oesophageal reflux and gastro-oesophageal reflux-related asthma. J Intern Med 2006, 259(3):323-331. PubMed PMID: 16476110

30. Davis RD Jr, Lau CL, Eubanks S, Messier RH, Hadjiliadis D, Steele MP, et al: Improved lung allograft function after fundoplication in patients with gastroesophageal reflux disease undergoing lung transplantation. J Thorac Cardiovasc Surg 2003, 125(3):533-542. PubMed PMID: 12658195.

31. Tamhankar AP, Peters JH, Portale G, Hsieh CC, Hagen JA, Bremner CG, et al Omeprazole does not reduce gastroesophageal reflux: new insights using multichannel intraluminal impedance technology. J Gastrointest Surg: Offic J Soc Surg Aliment Tract 2004, 8(7):890-897. discussion 7-8. PubMed PMID: 15531244

32. Doumit M, Krishnan $U$, Jaffe A, Belessis Y: Acid and non-acid reflux during physiotherapy in young children with cystic fibrosis. Pediatr Pulmonol 2012, 47(2):119-124. PubMed PMID: 22241570.

33. Brodzicki J, Trawinska-Bartnicka M, Korzon M: Frequency, consequences and pharmacological treatment of gastroesophageal reflux in children with cystic fibrosis. Med Sci Monit 2002, 8(7):CR529-CR537. PubMed PMID: 12118204

34. Elkins MR, Robinson M, Rose BR, Harbour C, Moriarty CP, Marks GB, et al: A controlled trial of long-term inhaled hypertonic saline in patients with cystic fibrosis. New Engl J Med 2006, 354(3):229-240. PubMed PMID: 16421364.

35. McCoy KS, Quittner AL, Oermann CM, Gibson RL, Retsch-Bogart GZ, Montgomery AB: Inhaled aztreonam lysine for chronic airway Pseudomonas aeruginosa in cystic fibrosis. Am J Respir Crit Care Med 2008, 178(9):921-928. PubMed PMID: 18658109

doi:10.1186/1471-2466-14-21

Cite this article as: DiMango et al:: Effect of esomeprazole versus placebo on pulmonary exacerbations in cystic fibrosis. BMC Pulmonary Medicine 2014 14:21

\section{Submit your next manuscript to BioMed Central and take full advantage of:}

- Convenient online submission

- Thorough peer review

- No space constraints or color figure charges

- Immediate publication on acceptance

- Inclusion in PubMed, CAS, Scopus and Google Scholar

- Research which is freely available for redistribution

Submit your manuscript at www.biomedcentral.com/submit
C Biomed Central 